\section{ESTUDIO Y COMPOSICIÓN DE NUEVE ESTATUILLAS CHINAS Y JAPONESAS DEL MUSEO NACIONAL DE CIENCIAS NATURALES APORTADAS POR D. JUAN DE CUELLAR EN EL SIGLO XVIII}

\author{
Javier García-Guinea \\ Profesor de Investigación CSIC (MNCN) \\ guinea@mncn.csic.es \\ Julio González-Alcalde \\ Conservador de las colecciones de Bellas Artes y Arqueología \\ Industrial MNCN (CSIC) \\ jga@mncn.csic.es \\ Aurelio Nieto Codina \\ Conservador de la colección de Geología MNCN (CSIC) \\ Aureo4@mncn.csic.es \\ Fondo documental: Archivo MNCN \\ Fondo gráfico: Servicio de Fotografía MNCN
}

\section{STUDY AND COMPOSITION OF NINE CHINESE AND JAPANESE STATUETTES AT THE NATIONAL MUSEUM OF NATURAL SCIENCES, DONATED BY JUAN DE CUELLAR IN THE 18TH CENTURY}

Cómo citar este artículo/ Citation: García Guinea, J.; González Alcalde, J.; Nieto Codina, A. (2013). “Estudio y composición de nueve estatuillas chinas y japonesas del Museo Nacional de Ciencias Naturales aportadas por D. Juan de Cuellar en el siglo XVIII". Arbor, 189 (762): a059. doi: http://dx.doi.org/10.3989/ arbor.2013.762n 4010

Recibido: 4 marzo 2013. Aceptado: 5 junio 2013.

RESUMEN: Se presenta un estudio histórico y de caracterización química y molecular por técnicas no destructivas, ESEMEDS y Raman, de nueve esculturas de pequeño tamaño, fabricadas en esteatita, antigua denominación de minerales blandos y untuosos como talco y pirofilita, conservadas en el Museo Nacional de Ciencias Naturales (MNCN). Se concluye que dos
Copyright: (c) 2013 CSIC. Este es un artículo de acceso abierto distribuido bajo los términos de la licencia Creative Commons Attribution-Non Commercial (by-nc) Spain 3.0.
ABSTRACT: This paper describes a historical study combined with a non-destructive chemical and molecular characterisation (using ESEM-EDS and Raman spectroscopy) of nine small sculptures. The specimens kept in the National Museum of Natural Sciences (MNCN institution) are composed of steatite or soapstone, a soft and unctuous mineral containing talc and 
especímenes son de pirofilita y procedentes de Japón, mientras que las otras siete son de talco con ornamentación de procedencia China. Las muestras de talco de China tienen calcita con algo de cobre, típica de metamorfismo de dolomías, mientras que las pirofilitas tienen $\mathrm{Pb}, \mathrm{Fe}, \mathrm{Cl}, \mathrm{As}, \mathrm{P}, \mathrm{S}, \mathrm{Na}$ y $\mathrm{Ca}$, elementos químicos de origen hidrotermal de rocas félsicas más característico de Japón. Las estatuillas fueron aportadas al RGHN desde Filipinas, en el siglo XVIII, por D. Juan de Cuellar, expedicionario y botánico español, de quien se incluye un recorrido por su biografía y actividades científico-económicas. Estas piezas son la expresión de la tendencia al coleccionismo de objetos orientales imperante en la época de la llustración.

PALABRAS CLAVE: RGHN; MNCN; Ilustración; talco; pirofilita; esteatita; estatuillas; D. Juan de Cuellar; Filipinas; siglo XVIII; productos lapidarios.

\section{INTRODUCCION}

\subsection{Definiciones de esteatita, talco y pirofilita}

La etimología de la palabra ESTEATITA según el Diccionario de la Real Academia Española proviene del

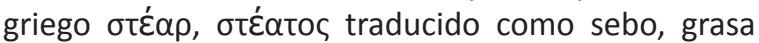
sólida y definido como "Mineral de color blanco y verdoso, suave, y tan blando que se raya con la uña. Es un silicato de magnesio, empleado como sustancia lubricativa, y, con el nombre de jabón de sastre, sirve para hacer señales en las telas". Dentro del sistema anglosajón, el término esteatite se traduce como piedra jabón (soap-stone) y la definen como talco, sin más detalles. Sin embargo, es evidente que algunas definiciones de palabras antiguas como "esteatita" aluden a propiedades físicas sencillas como "grasa sólida" que cumplen minerales diferentes, con composiciones químicas diferentes, estructuras cristalinas diferentes y orígenes geológicos diferentes, aunque sus texturas de grano fino, su untuosidad, su aspecto y muchas de sus aplicaciones sean las mismas. Es el caso de la esteatita-talco y de la esteatita-pirofilita. En España, la esteatita es talco porque casi no existe pirofilita, pero en Japón, es probable que ocurra lo contrario, y la esteatita sea pirofilita, porque, allí hay poco talco y mucha pirofilita. Desde el punto de vista de la mineralogía científica el TALCO es un silicato de magnesio hidratado de fórmula $\mathrm{Mg}_{3} \mathrm{Si}_{4} \mathrm{O}_{10}(\mathrm{OH})_{2}$ con estructuras trilaminares de iones $\mathrm{Mg}^{2+}$ en coordinación trioctaétrica y simetría monoclínica $(2 / \mathrm{m})$ con grupo espacial $\mathrm{C}_{2 / \mathrm{c}}$ formado por alteración hidrotermal de silicatos magnésicos no aluminosos (webmineral.com/data/ Talc.shtml). La PIROFILITA es un silicato hidratado de pyrophyllite. We found that two of the specimens are made of pyrophyllite from Japan while the other seven are talc carved with Chinese-style ornamentation. These talc specimens from China include calcite formed by dolomite metamorphism, while the pyrophyllite samples show $\mathrm{Pb}, \mathrm{Fe}, \mathrm{Cl}, \mathrm{As}, \mathrm{P}, \mathrm{S}, \mathrm{Na}$ and $\mathrm{Ca}$, chemical elements more characteristic of hydrothermal alterations of felsic rocks from Japan. The statuettes were brought to what was then the RGHN from Philippines in the eighteenth century by Juan de Cuellar. The paper includes a short biography of this Spanish explorer and botanist and an account of his scientific and economic activities. These specimens are an excellent example of the Enlightenment fashion for collecting Asian objects.

KEYWORDS: RGHN; MNCN; Enlightenment; Talc; Pyrophyllite; Steatite; Statuettes; Juan de Cuellar; Philippines; 18th Century; stone products.

aluminio de fórmula $\mathrm{Al}_{2} \mathrm{Si}_{4} \mathrm{O}_{10}(\mathrm{OH})_{2}$ con estructuras trilaminares de iones $\mathrm{Al}^{3+}$ en coordinación dioctaétrica y simetría triclínica (ī) con grupo espacial Pī formado por magmatismo félsico con alteraciones hidrotermales de rocas compuestas por cuarzo y sericita, como en el caso de Nagano, Japón (webmineral.com/data/ Pyrophyllite.shtml) (Deer et al., 1976).

\subsection{Origen geológico, producción, yacimientos, usos y reservas}

Desde el punto de vista de su origen geológico los yacimientos de talco de interés comercial más comunes están asociados: (1) a rocas dolomías afectadas por metamorfismo o (2) a rocas ígneas ultrabásicas alteradas hidrotermalmente. En el primer caso, podemos imaginar de forma simplificada estratos de dolomía $\mathrm{CaMg}\left(\mathrm{CO}_{3}\right)_{2}$ y de cuarzo $\mathrm{SiO}_{2}$ reaccionando a bajas temperaturas junto con agua caliente, mediante la siguiente reacción química: $3 \mathrm{CaMg}\left(\mathrm{CO}_{3}\right)_{2}$ (dolomía) $+4 \mathrm{SiO}_{2}+\mathrm{H}_{2} \mathrm{O} \rightarrow \mathrm{Mg}_{3} \mathrm{Si}_{4} \mathrm{O}_{10}(\mathrm{OH})_{2}$ (talco) $+3 \mathrm{CaCO}_{3}+$ $3 \mathrm{CO}_{2}$. En el segundo caso, podemos imaginar unas rocas ultrabásicas alteradas, o sea serpentina de fórmula $\mathrm{Mg}_{3} \mathrm{Si}_{2} \mathrm{O}_{5}(\mathrm{OH})_{4}$ reaccionado con el burbujeo de $\mathrm{CO}_{2}$ del agua caliente hidrotermal mediante la siguiente reacción química: $2 \mathrm{Mg}_{3} \mathrm{Si}_{2} \mathrm{O}_{5}(\mathrm{OH})_{4}+3 \mathrm{CO}_{2} \rightarrow$ $\mathrm{Mg}_{3} \mathrm{Si}_{4} \mathrm{O}_{10}(\mathrm{OH})_{2}$ (talco) $+3 \mathrm{MgCO}_{3}$ (magnesita) $+3 \mathrm{H}_{2} \mathrm{O}$ (García Guinea, Martínez Frías, 1992). Estos modelos geológicos son muy comunes en la Naturaleza proporcionando muchos afloramientos de talco, por ejemplo en USA, Finlandia, Francia, Italia, Austria, China, India, España, etc. España produce unas 50.000 toneladas de talco al año con tres empresas mineras situadas en las provincias de León, Gerona y Málaga. Ibérica de 
Talcos (IBETASA) extrae talco en Puebla de Lillo (León) y lo transforma y microniza en su planta de tratamiento de Boñar (León). Su producción va destinada a las industrias papeleras, pinturas, plásticos y fertilizantes. La producción de talco en España aproximadamente se distribuye de la siguiente manera: Cargas 27,8\%, Exportación 6,6\%, Cerámica 40,6\%, Absorbentes y decolorantes 8,8\%, Química Básica 4\%, Alimentarias $1,6 \%$, pigmentos $2,5 \%$, Fertilizantes $4,8 \%$, Cosmética $3,3 \%$ (Figura 1). Existen fuertes variaciones de cifras de producción, cambios de usos y apertura y cierre de minas. La producción mundial de talco y pirofilita llega a los 9 millones de toneladas, con una distribución aproximada de China 26\%, Japón 15\%, USA 11\%, Corea del Sur $9 \%$, Brasil 6\%, Rusia 5\%, India 4\%. Las producciones de Japón y Corea corresponden mayoritariamente a pirofilita. Japón es el primer productor del mundo de pirofilita y el primer importador del mundo de talco. El talco y la pirofilita se usan principalmente como materia prima cerámica, porque permiten mayores temperaturas de cocción y procesos más rápidos produciendo productos acabados más blancos. En la industria de pinturas se utiliza como cargas y en la del papel aporta más peso y opacidad produciendo papel de muy buena impresión y una textura superficial de gran calidad. En cosméticos y farmacéuticas necesitan los talcos de mayores calidades para garantizar suavidad, tacto agradable, buen color y estabilidad química, sin impurezas. También se utiliza para papel alquitranado, en plásticos y cauchos. Las mayores reservas mineras de talco y pirofilita están en Estados Unidos (36\%) y Japón (35\%).

\subsection{Biografía y expedición de D. Juan de Cuellar}

Juan José Ruperto de Cuellar y Villanueba (Aranjuez, 1739, Ilocos, Filipinas, 1801) regentó una farmacia desde 1760 en la calle de Atocha de Madrid, esquina a la calle Concepción Jerónima, y fue miembro del Colegio Real de Farmacéuticos, aunque en 1781, no pudo mantener su establecimiento por razones financieras. En el Real Jardín Botánico de Madrid tomó clases de 1783 a 1784 , en el marco de un programa para aumentar los conocimientos científicos de los farmacéuticos. En Cádiz, se ocupó del reparto de los materiales aportados por la expedición de Hipólito Ruíz López y José Pavón, y José Dombey a Perú y Chile (1777-1778). Fueron Ruíz y Pavón los que en agradecimiento a su trabajo, le homenajearon con la dedicatoria del género Cuellaria, en la Flora Peruviana y Chilensis (Steele, 1982; Gracia, Puerto, 1995). El 2 de mayo de 1785, la Real Sociedad de Medicina de Sevilla le nombró catedrático de botánica en el Jardín Botánico de Sevilla, plaza, a la que se había presentado (Bañas, 2000), y a la que renunció para ocupar el puesto de botánico de la expedición a las Islas Filipinas (Puerto, 1988: 228-232).

Esta expedición tuvo sus orígenes administrativos el 10 de marzo de 1785, cuando el rey Carlos III firmó, por consejo de José Patiño, una Real Orden por la que se constituía la Real Compañía de Filipinas, con la finalidad de investigar y explotar los recursos naturales de las Islas. Era una sociedad político-mercantil que serviría, según Francisco Cabarrús, de nexo desde Filipinas, al comercio español entre América y Asia.

Figura 1. Roseta de aplicaciones de las esteatitas. Modificado y traducido de un original de Robertson RHS (1960)

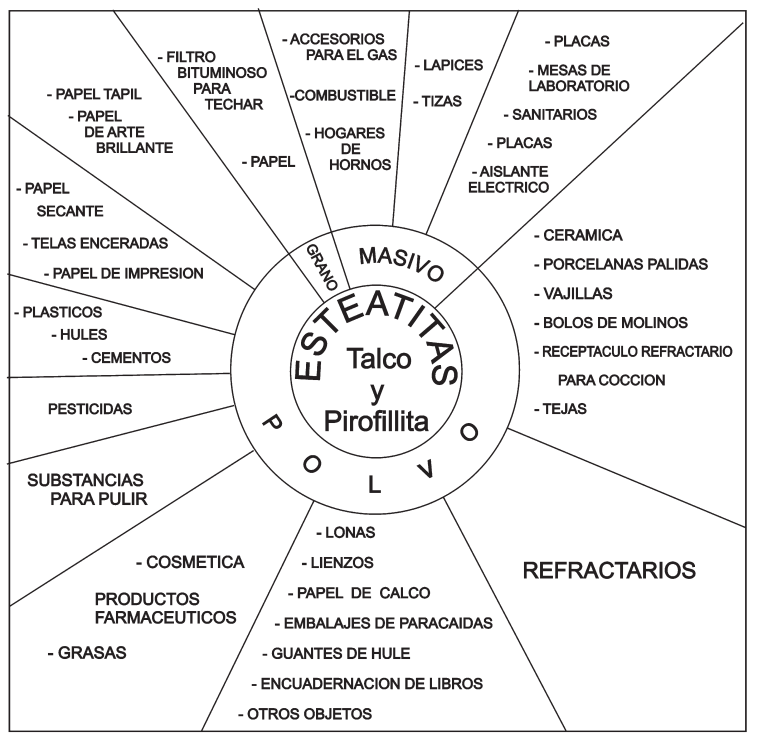


Esta Real Compañía solicitó un investigador de la flora del Archipiélago a José de Gálvez, ministro de Indias. Gálvez recurrió al director del Real Jardín Botánico de Madrid, Casimiro Gómez Ortega, quien nombró a Juan de Cuellar Botánico Real y Naturalista de las Islas Filipinas, pero sin sueldo..., el 19 de noviembre de 1785, al servicio de la Compañía de Filipinas. Por lo tanto, Juan de Cuellar había sido contratado por una compañía privada, pero con título oficial y encargos del Jardín Botánico y del RGHN (Puerto, 2008).

Las circunstancias de esta expedición y su desenvolvimiento han sido explicitadas con gran precisión (San Pío Aladrén, 1997; Díaz Trechuelo, 1997; Bañas, 2000; Puerto, 2008), por lo que basándonos en estos autores, y de forma muy sintetizada, podemos referirnos a los siguientes datos:

En enero de 1786, Cuellar se embarca en Cádiz a bordo del Águila Imperial con destino a Cavite y en agosto está en Manila. Recorre diversas zonas de las Islas e investiga los cultivos de interés para la Real Compañía, como el algodón, añil, cacao, café, moreras, entre otros. Además envía varios cajones a España con producciones naturales, curiosidades y objetos muy variados de Filipinas y de otras partes de Asia. Iban destinadas al RGHN, dirigido entonces por D. Pedro Franco Dávila (1711-1786), que solicitó a Cuellar esos envíos para su museo y elogió, ante el conde de Floridablanca, su valía como botánico, minerólogo y zoólogo, hasta conseguir que Cuellar fuera un corresponsal del RGHN. En palabras de Dávila, se "confía plenamente en su inteligencia para remitir y adquirir todo lo raro que se encuentre en aquellas islas."

Sin embargo, por Real Orden de enero de 1788, Cuellar tendrá que centrar su actividad en el fomento de las plantaciones de canela y nuez moscada. A este respecto, el hacendado español Francisco Xavier Salgado era propietario de una plantación de canelos en sus propiedades de Calavang. La intención era acabar con el monopolio holandés de estos productos, pero los obtenidos en Filipinas no tenían la calidad de los producidos por los holandeses. Los boticarios apreciaban mucho esta especia, por sus aceites esenciales. Comúnmente, se tomaba con cacao y se bebía el chocolate con espuma, cosa inviable con la canela filipina, porque cortaba la bebida por un exceso de mucílagos o babaza, por lo que si se pretendía utilizar, esos defectos deberían subsanarse, según Puerto.

No pudo obtener beneficios de las plantaciones de canela, no se atendió su propuesta de realizar una expedición botánica por todo el Archipiélago filipino y tampoco su proposición en 1788, de organizar un Jardín Botánico. No le aumentan la disponibilidad económica porque, según la Compañía, sus resultados no han supuesto utilidad para ella. Sin embargo le ponen al frente de un terreno para plantar especies con fines comerciales. La Real Compañía, ambigua institución privada, pero proveedora de la Corona, le tiene como asalariado, siendo enviado real sin salario, y desde 1789 prácticamente no solicitó sus servicios y se desinteresó por él, si es que estuvo interesada alguna vez. Esta ambivalencia de la Corona y de la Real Compañía distaba de favorecer los intereses de ambas y, desde luego, no favorecía tampoco los de Cuellar.

Durante ese tiempo recibió la visita de la expedición de Alejandro Malaspina, cuyas corbetas Atrevida y Descubierta, fondearon en Cavite el 24 de marzo de 1792, y recibió información de Cuellar relacionada con los recursos naturales filipinos.

En 1793 la Real Compañía decidió no continuar con el mantenimiento de las plantaciones de Calavang y el 19 de junio, una Real Orden suprimía la Junta de Gobierno de la Real Compañía en Manila. Cuellar fue destituido, por lo que protestó ya que era el enviado real oficial para las investigaciones botánicas, y su expulsión parecía contradecir las intenciones reales. Se buscó una solución para él por parte del Gobernador de Filipinas, que le nombró en 1797 comisionado del alumbrado público de Manila, después se le encargó la alcaldía de llocos para que fomentase el cultivo de algodón, lo que indica una cierta protección por parte del ministerio. La Compañía le nombró su representante en llocos y superintendente de las fábricas de lonas. En estos cargos estudió la geografía de la provincia, lo que facilitó su reorganización por el gobierno.

Este gran naturalista del denominado Siglo de las Luces, motor de la expedición botánica a las Islas Filipinas, víctima de aquellas administraciones y empresas, falleció en Illocos a finales de 1801.

\subsection{Envíos de las esculturas de esteatita al RGHN}

Como continuación de la antigua y amplia tradición del coleccionismo real, nobiliario y eclesiástico (Gaya Nuño, 1955; id. 1969; Checa, Morán, 1985; Sanz Pastor, 1990; Bolaños, 1997), en Europa occidental, a finales del siglo XVIII, se estaban aumentando las grandes colecciones históricas que hoy llenan los museos, si bien en el marco de la llustración para la que primaba el coleccionismo científico, aunque los monarcas y otros coleccionistas continuaban siendo importantes mecenas (Hernández, 1994). Tanto los objetos que recopi- 
laban los viajeros del Gran Tour por Europa, como los envíos de las compañías de indias sobre todo inglesas, francesas y holandesas, proveían a las colecciones de cuadros, esculturas, materiales naturales, artes decorativas y producciones impresas. En España, se inserta en este ámbito el RGHN que parte de la colección de su primer director, D. Pedro Franco Dávila, adquirida por el rey Carlos III (Villena, Sánchez Almazán, Muñoz, Yagüe, 2008). Por el discurrir de los acontecimientos históricos (González-Alcalde, Izquierdo, Sánchez ChiIlón, Velasco, 2011: 57-64), es casi un milagro que el MNCN conserve algunos de estos productos llegados de Oriente, testimonio de unas formas artísticas inspiradas en las tradiciones asiáticas, pero pensadas sobre todo para su venta a comerciantes y viajeros foráneos. El centro de producción más importante de estos objetos era el sur de China, donde se conectaban las rutas comerciales abastecedoras de cerámicas y otros objetos suntuarios a Europa y zonas de Asia, como Indonesia, India y Japón que también tenían una demanda importante para los materiales creados en China (VV.AA., 2003; VV.AA., 2009).

En este contexto, Cuellar (Calatayud, 1984: 226233) realizó envíos muy variados con destino al RGHN, actual MNCN, de dibujos y producciones de la Naturaleza, como conchas, minerales, resinas, semillas, entre otras. Sin embargo, los materiales herborizados por Cuellar fueron escasos, pero superó este handicap adquiriendo productos de diversa índole y manufacturas, y enviando cajones con producciones asiáticas que podrían calificarse de "rarezas", teniendo en cuenta que lo demandado en un principio desde España eran las producciones naturales. Esas "rarezas" incluían objetos trabajados en minerales, entre los que cabe destacar las figuras de esteatita (GonzálezAlcalde, Nieto, García-Guinea, 2012: 12-16) enumeradas por Cuellar en un escrito de 20 de enero de 1790, firmado en Manila (Calatayud, 1984, no. 476: 231). Constan como enviadas en 1791 a bordo de la fragata Placeres. A este respecto consta un oficio, firmado en Palacio, de 20 de julio, del conde de Floridablanca al vicedirector del RGHN, para que reciba cinco cajones, remitidos desde Filipinas por Cuellar y que envía desde Cádiz Manuel González Guiral, el cual notifica en Cádiz, a 5 de agosto, a Josep Clavijo la remesa que va a recibir con el carromatero Francisco Cerdá, con factura para que abone los gastos de 382 reales y $25 \mathrm{mrs}$. de vellón. La factura fue entregada por Juan Berton, y firmada por Manuel González en nombre de Francisco Cerdá el 22 de agosto. Sin embargo, el 23 de agosto se escribe al conde de Floridablanca desde el RGHN explicándole que es excesiva la cantidad de figuras de esteatita enviadas por Cuellar y que habría sido mejor enviar dos o tres como muestra de cómo trabajan en China la esteatita. Además no parece que gustaron en el RGHN porque en el escrito se indica que se le notifique a Cuellar que procure no remitir sino cosas realmente curiosas por su naturaleza o novedad respecto a España o por la antigüedad (Calatayud, 1984, no. 478: 231).

EI RGHN de 1791 presentaba la problemática de las frecuentes ausencias de su director Eugenio Izquierdo de Rivera y Lazaún, sucesor de Dávila, desde su nombramiento el 24 de mayo de 1786 por el conde de Floridablanca. Estas ausencias se debían a las actividades políticas de Izquierdo, secretario del Duque de Alcudia (Manuel Godoy). Quien dirigía realmente el RGHN era el vicedirector Josep Clavijo (M. C. Velasco, comunicación personal). No parece que Clavijo entendiese las variadas lecturas que podrían hacerse con estas piezas. Dávila, en cambio, sí tenía muchísimo interés en este tipo de producciones, como consta en la carta de 21 de noviembre de 1785 , que dirige a Cuellar con la memoria que, de orden del conde de Floridablanca, ha formado en relación a los objetos que debe adquirir en Filipinas y enviar a Madrid. Entre estas peticiones figuran estatuillas y otros objetos (Calatayud, 1984, no. 467: 228). Se documenta la llegada de esta clase de piezas, como consta en la carta fechada en San Ildefonso el 29 de agosto de 1777, en la que Almerico Pini se dirige a Dávila y le indica que entre las piezas procedentes de Filipinas, han llegado muy fragmentadas dos figuras chinas (Calatayud, 1987, no. 452: 166), a la que le responde Dávila que las dos figuras chinas han sido arregladas y quedan colocadas en el Gabinete (Calatayud, 1987, no. 458: 167).

\section{MUESTRAS Y TÉCNICAS DE CARACTERIZACIÓN}

En este trabajo se han estudiado nueve estatuillas pequeñas y medianas, trabajadas en esteatitas-talco procedentes de China y esteatitas-pirofilita procedentes de Japón con las típicas características de los filosilicatos de grano fino de esteatita, es decir muy blandos, ligeros, suaves, untuosos, jabonosos al tacto y fáciles de rayar con la uña (Figura 2). Las estatuiIlas fueron analizadas de forma no destructiva en un equipo de ESEM-EDS de marca FEI Quanta operando a bajo vacío que permite analizar a alta resolución haciendo análisis químicos por EDS de muestras no conductoras a los electrones como las esteatitas. El equipo tiene un detector de electrones retro-dispersados (BS) y un espectrómetro de energía dispersiva de ra- 
yos X (EDS) para análisis químicos puntuales. El estudio por espectroscopia micro-Raman se realizó en un Microscopio ThermoFischer DXR Raman, que permite analizar con resolución espacial de una micra. Se seleccionó un objetivo 50X con una fuente láser de 532 $\mathrm{nm}$ a $6 \mathrm{~mW}$ de potencia en un modo de láser al 100\%. Ambos microscopios, electrónico y óptico-Raman dis- ponen de cámaras de trabajo relativamente grandes suficientes para analizar las estatuillas. Los productos de lapidarios históricos procedentes de Asia se presentan muy puros con colores blancos y también coloreados por óxidos cromóforos de hierro, cobre y plomo de colores verdes, rojos, amarillos y marrones (Tablas 1 y 2 ).

Figura 2. Nueve estatuillas procedentes de China y Japón

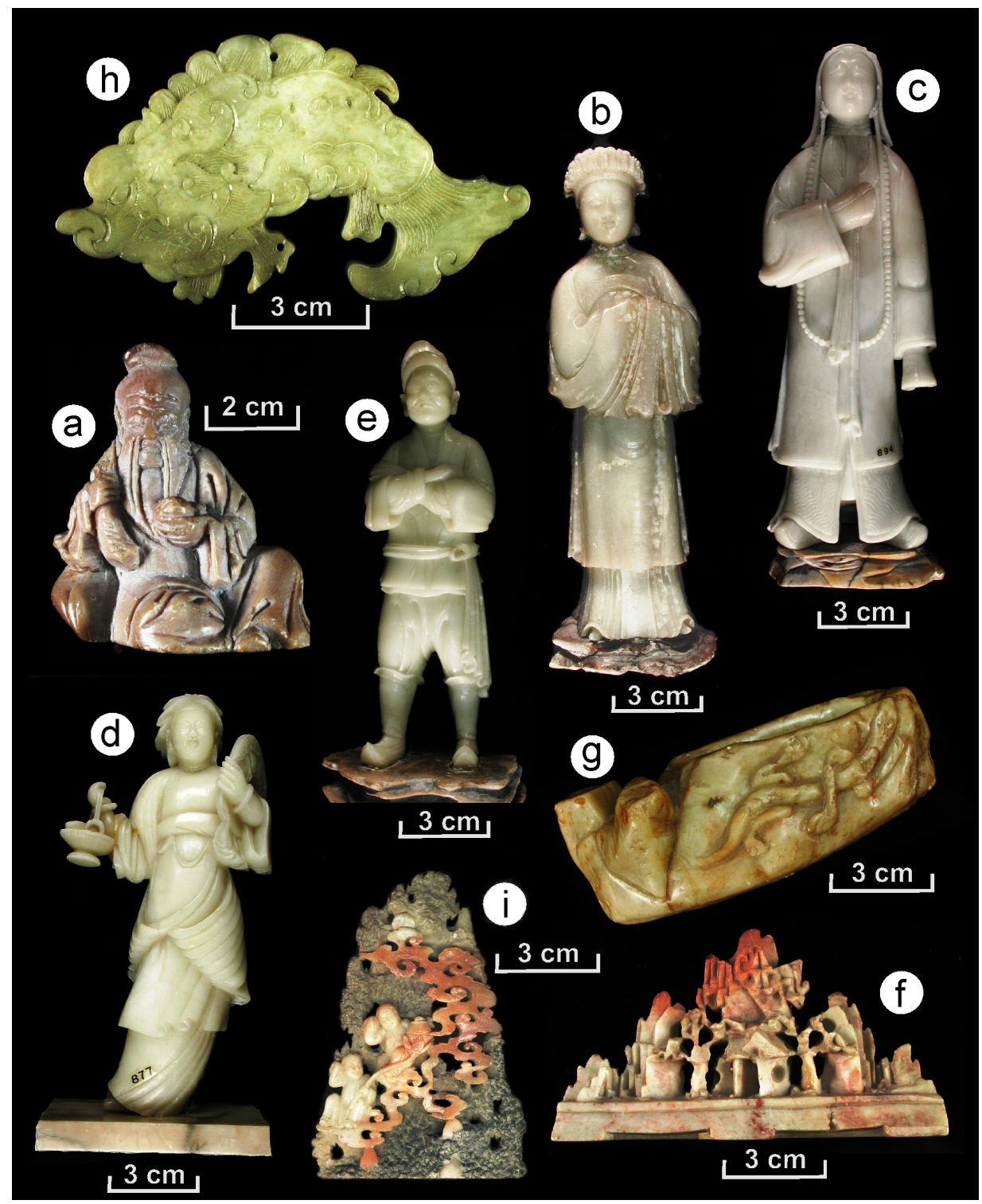

(a) Anciano sedente con peinado recogido, barba larga y bigote. (b) Figura estante con gorro historiado y túnica, representativa de las altas clases sociales chinas. (c) Figura estante con túnica y collar largo, representativa de las altas clases sociales chinas. (d) Figura estante que sujeta un objeto redondo en su mano izquierda y en la derecha un recipiente parecido a un frutero con una botella y una escudilla en su interior. (e) Figura masculina estante con zapatos puntiagudos y brazos cruzados sobre el pecho. (f) Paisaje con árboles y pequeñas construcciones. (g) Recipiente decorado con un lagarto. (h) Pez con dos orificios en la aleta superior y en la inferior, con posible función para colgar o sujetar. (i) Posible pared rocosa con nubes o humo y dos figuras con un loto en las manos. 
Tabla 1. Análisis químicos por EDS-ESEM de las figuras de composición talco

\begin{tabular}{|c|c|c|c|c|c|c|c|}
\hline Elemento & 1-anciano & 2-mangas & 3-collar & 4-cesto & 5-cruzado & 7-lagarto & 8-pez \\
\hline $\mathrm{O} \%$ & 50,43 & 50,6 & 51,48 & 51,8 & 50,01 & 50,22 & 51,03 \\
\hline $\mathrm{Mg} \%$ & 19,11 & 17,97 & 16,29 & 19,2 & 19,31 & 19,45 & 19,52 \\
\hline $\mathrm{Al} \%$ & 0 & 0,84 & 0,64 & 0 & 2,13 & 0 & 0 \\
\hline $\mathrm{Si} \%$ & 29,32 & 30,59 & 29,55 & 28,76 & 28,33 & 29,44 & 29,57 \\
\hline $\mathrm{Ca} \%$ & 1,14 & 0 & 1,58 & 0 & 0 & 0,89 & 0 \\
\hline $\mathrm{Cu} \%$ & 0 & 0 & 0,46 & 0,24 & 0,22 & 0 & 0 \\
\hline Totales & 100 & 100 & 100 & 100 & 100 & 100 & 100,12 \\
\hline
\end{tabular}

Tabla 2. Análisis químicos por EDS-ESEM de las figuras de composición pirofillita

\begin{tabular}{|c|c|c|c|c|}
\hline Elemento & 6-arbol & 9-loto blanco & 9-loto rojo1 & 9-loto rojo2 \\
\hline $\mathrm{O} \%$ & 53,92 & 51,31 & 51,14 & 46,8 \\
\hline $\mathrm{Mg} \%$ & 0,54 & 0 & 0 & 0,43 \\
\hline $\mathrm{Al} \%$ & 14,73 & 14,36 & 14,72 & 10,69 \\
\hline $\mathrm{Si} \%$ & 30,34 & 32,28 & 32,43 & 22,54 \\
\hline $\mathrm{Ca} \%$ & 0,12 & 0,87 & 0,53 & 5,98 \\
\hline $\mathrm{Na} \%$ & 0 & 0,32 & 0,55 & 1,32 \\
\hline $\mathrm{Fe} \%$ & 0 & 0 & 0,25 & 0,7 \\
\hline $\mathrm{S} \%$ & 0 & 0,87 & 0,4 & 4,54 \\
\hline $\mathrm{Cu} \%$ & 0,35 & 0 & 0 & 0 \\
\hline $\mathrm{P} \%$ & 0 & 0 & 0 & 0,59 \\
\hline $\mathrm{Cl} \%$ & 0 & 0 & 0 & 0,94 \\
\hline $\mathrm{K} \%$ & 0 & 0 & 0 & 0,67 \\
\hline $\mathrm{As} \%$ & 0 & 0 & 0 & 0,5 \\
\hline $\mathrm{Pb} \%$ & 0 & 0 & 0 & 4,3 \\
\hline Totales & 100 & 100 & 100 & 100 \\
\hline
\end{tabular}

\section{RESULTADOS Y CONCLUSIONES}

Los análisis químicos de las estatuillas se realizaron por energías dispersivas de rayos $X$ (EDS-ESEM) (Tablas 1 y 2) y desde el punto de vista molecular, mediante espectroscopia Raman (Figura 3).

Las figuras presentan temas usuales de la cultura china: la flor de loto, paisajes idealizados, peces dragón, lagarto y, destacando dentro del conjunto, esculturas que representan figuras masculinas y femeninas ataviadas con trajes exóticos y aderezos decorativos. Las figuras tenían añadidos elementos que es de lamentar no se hayan conservado, realizados en otros materiales, posiblemente metálicos, que incrementaban el valor iconográfico de estas obras: pipas de fumar, coronas, bastones, entre otros.
Representan una figura masculina, aparentemente un anciano sedente y apoyado con el codo del brazo derecho en una roca, con peinado recogido y bigote y barba largos, afeitado en el centro de bigote y barbiIla, que sujeta dos objetos, uno en cada mano (MNCN 14846, Fig. 2a); una figura estante vestida como las altas clases sociales chinas, con gorro historiado y túnica que le tapa las manos juntas a la altura del pecho (MNCN 14828, Fig. 2b); una figura estante con la cabeza cubierta y vestimenta de las altas clases sociales chinas, con túnica sobre la que figura un pañuelo, lleva pendientes, collar largo hasta más abajo de la cintura y las manos tapadas por las mangas, se lleva la mano derecha a la altura del corazón y el brazo izquierdo hacia abajo paralelo al cuerpo (MNCN 14832, Fig. 2c); una figura estante con la cabeza cubierta o 
con un peinado irregular, con vestido largo, que sujeta con su mano y brazo izquierdos un objeto redondo y con la mano derecha el asa de una especie de recipiente parecido a un frutero con una botella y una escudilla en su interior (MNCN 14827, Fig. 2d); una figura masculina estante con bigote, los brazos cruzados y las piernas separadas para sujetarse, usa gorro, camisa sujeta con una tela anudada, pantalones hasta las rodillas incluidas y zapatos con la punta hacia arriba (MNCN 14833, Fig. 2e); un paisaje con rocas árboles y posiblemente una pequeña construcción (MNCN 14843, Fig. 2f); un recipiente decorado con un lagarto (MNCN 14845, Fig. 2g); un pez con dos orificios practicados en la aleta superior y en la inferior, con posible función para colgar o sujetar (MNCN 14844, Fig. $2 \mathrm{~h}$ ), y una posible pared rocosa triangular con nubes o humo y dos figuras humanas con una flor de loto en las manos (MNCN 795, Fig. 2i).

Los análisis químicos realizados por energías dispersivas de las figuras de esteatita $(a, b, c, d, e, g$, h) (Tabla 1) muestran elevados contenidos de silicio (promedio 29\%) y de magnesio (promedio 18\%) lo que apunta hacia talco con cantidades accesorias de cobre $(0,30 \%)$, aluminio (1\%) y calcio $(1 \%)$. El calcio se corresponde con calcita procedente de una antigua dolomía metamorfizada y con los mejores yacimientos de talco, muy probablemente de China. El cobre quizás pueda explicar unas manchas de tonalidades verde azuladas en estos talcos. Sin embargo los análisis químicos de otras dos estatuillas de esteatita (f-árboles e i-dos hombres con flor de loto) (Tabla 2) muestran mayores contenidos en silicio (aprox. 30\%) y aluminio (aprox. $14 \%$ ) y casi nada de magnesio $(0,3 \%)$ lo que apunta hacia pirofilitas. En las zonas de tonos rojizos, los análisis químicos muestran enriquecimiento en plomo $(4 \%)$, hierro $(0,7 \%)$ que seguramente actúan como elementos cromóforos explicando los colores marrones rojizos. También tienen otros elementos como $\mathrm{Cl}, \mathrm{As}, \mathrm{P}, \mathrm{S}, \mathrm{Na}, \mathrm{Ca}$, etc., atribuibles a un origen hidrotermal de rocas félsicas muy abundantes en Japón. El estilo artístico, la composición química y las propiedades organolépticas de ambas estatuillas (f, i) apuntan hacia tallas de pirofilita procedentes de Japón. Sin embargo las figuras de esteatita-talco ( $a, b$, $c, d, e, g, h)$ muy probablemente proceden de China. Los análisis por espectroscopia Raman de las estatuillas (Figura 3) refuerzan estas hipótesis, por ejemplo, los espectros 3-a y 3-b son de calcita y de talco de la muestra b-collar tratándose de una muestra limpia y grande, de probable procedencia China. El resto de las esteatitas-talco inferidas por los análisis químicos por EDS, efectivamente ofrecen espectros Raman de talco, por ejemplo los que se muestran en las Figuras 3-c y 3-d, y finalmente, los espectros 3-e y 3-f son de pirofilita con su característico pico de vibración Raman a $262 \mathrm{~cm}^{-1}$ (Figura 3).

Figura 3. Espectros Raman de minerales de algunas estatuillas

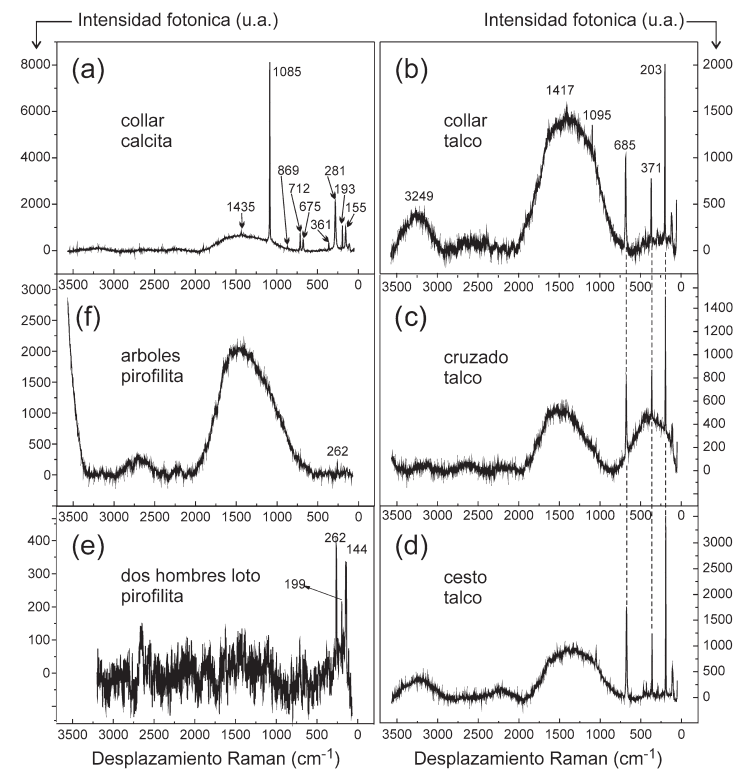

(a) Calcita bien cristalizada de la figura de esteatita-talco con collar, (b) Talco de la figura de esteatita-talco con collar, (c) Talco de la figura de brazos cruzados, (d) Talco de la figura con cesto, (e) Pirofilita de la figura de dos hombres con flor de loto, (f) Pirofilita de la figura con árboles (pico a $262 \mathrm{~cm}^{-1}$ ). 
Bañas, Mạ. B. (2000). Una Historia Natural de Filipinas: Juan de Cuellar, ¿1739?-1801. Barcelona: Ediciones del Serbal, S.A.

Bolaños, Mạ. (1997). Historia de los museos de España. Memoria, cultura y sociedad. Gijón: Trea.

Calatayud, Ma. A. (1984). Catálogo de las Expediciones y Viajes Científicos Españoles (siglos XVIII-XIX). Madrid: CSIC.

Calatayud, Mà. A. (1987). Catálogo de documentos del Real Gabinete de Historia Natural (1752-1786). Madrid: CSIC.

Checa, F.; Morán, M. (1985). El coleccionismo en España. Madrid: Arte Cátedra.

Deer, W.A.; Howie R.A.; Zussman, J. (1976). Rock-Forming Minerals. Vol. 3, 270 pags. London: Longman.

Díaz Trechuelo, Mạ. L. (1997). "La Expedición de Juan de Cuellar a Filipinas". En San Pío Aladrén, Mạ. Pilar de (coord.). La expedición de Juan de Cuellar a Filipinas. Lunwerg, Real Jardín Botánico, CSIC, Caja Madrid. Madrid.

García Guinea, J.; Martínez Frías, J. (coords.) (1992). Recursos minerales de España. Madrid: Editorial CSIC. 1448 pp.
Gaya Nuño, J. A. (1955). Historia y guía de los museos en España. Madrid: Espasa Calpe, S.A. (Segunda Ed. 1969).

González-Alcalde, J.; Izquierdo, I.; Sánchez Chillón, B.; Velasco, M. C. (2011). "Las tres sedes del Museo Nacional de Ciencias Naturales". Madrid Histórico, 34, julio/agosto. Madrid, 2011: 57-64.

González-Alcalde, J.; Nieto, A.; GarcíaGuinea, J. (2012). "Estatuillas chinas del Museo Nacional de Ciencias Naturales (MNCN). Ocho aportaciones orientales de D. Juan de Cuellar en el siglo XVIII". Madrid Histórico, 38, marzo/abril. Madrid.

Gracia, D. y Puerto, J. (dirs.) (1995). Flora Peruviana y Chilensis. Madrid: Gabriel de Sancha, 1798. Edición facsímil. Biblioteca de Clásicos de la Medicina y de la Farmacia española. Aranjuez. Doce Calles-Fundación Ciencias de la Salud.

Hernández Hernández, F. (1994). Manual de Museología. Madrid: Síntesis, pp. 41-42.

Puerto, J. (1988). La ilusión quebrada. Botánica, sanidad y política científica en la España llustrada. Barcelona: Serbal-CSIC.
Puerto, J. (2008). “Juan de Cuellar y la expedición botánica a las islas Filipinas". En Ciencia y Cultura de Rousseau a Darwin. Canarias: Fundación Canaria Orotava de la Ciencia. Consejería de Educación, universidades, cultura y deportes del Gobierno de Canarias.

Robertson, R. H. S. (1960). Minerals use guide. London: Ed. Cleaver-Hume Press, $44 \mathrm{pp}$.

Sanz Pastor, C. (1990). Museos y colecciones de España. Madrid: Ministerio de Cultura.

Steele, A. R. (1982). Flores para el Rey. La expedición de Ruiz y Pavón y la Flora del Perú (1777-1788). Barcelona: Ediciones del Serbal.

VV.AA. (2003). Oriente en palacio. Tesoros asiáticos en las colecciones reales españolas. Madrid: Patrimonio Nacional, Servicio de Publicaciones.

VV.AA. (2009). Orientando la mirada. Arte Asiático en las colecciones públicas madrileñas. Madrid: Ayuntamiento de Madrid, Conde Duque.

Villena, M.; Sánchez Almazán, J.; Muñoz, J.; Yagüe, F. (2008). El gabinete perdido. Madrid: CSIC. 